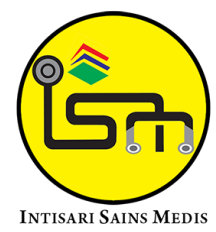

Published by Intisari Sains Medis

\title{
Diagnosis dan tatalaksana tromboangitis obliterans/penyakit buerger dengan fenomena raynaud
}

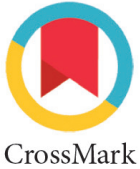

\author{
Tjok Ngurah Prasanta Adityaputra ${ }^{1 *}$, Bagus Ari Pradnyana Dwi Sutanegara², \\ Agung Pradnyana Suwirya ${ }^{2}$
}

\section{ABSTRACT}

Introduction: Thromboangitis obliterans (TAO) is segmental, non-atherosclerotic inflammatory disease involving small to moderate arteries, veins, and nerves of extremities. TA0 or Buerger's disease has very strong association with tobacco use. The adoption of stricter diagnostic criteria and reduced tobacco use have led to a decline in the number of new TAO patients in United States, Europe, and Asia. Typical TAO patients are young men with history of heavy smoking who present with limb ischemic symptoms before age 45 years. The most common symptoms are due to arterial occlusion disease, secondary vasospasm (Raynaud's phenomenon), and superficial thrombophlebitis. Clinical diagnosis of TAO requires exclusion of diseases that mimic this diseases such as atherosclerotic vascular disease, thromboembolic disease, and autoimmune diseases such as scleroderma. Therapeutic foundation

for TA0 is complete cessation of any tobacco use. The use of vasodilators is largely for palliative. Therapeutic anticoagulants have not been shown to be effective in the treatment of TAO. Nonetheless, some physicians have used anticoagulants in attempt to delay amputation and increase collateral flow in severe critical limb ischemia.

Case report: A 56 year old man complained of bluish and pain on the finger tips of both right and left hand. Smoking four packs a day. Dupplex ultrasound and CT scan of the superior limb angiography showed no abnormalities in the proximal artery. Echocardiography showed result within normal limit.

Conclusion: These findings suggest diagnosis of thromboangitis obliterans with Raynaud's phenomenon, even if he is over 45 years of age.
'Residen IImu Penyakit Jantung dan Pembuluh Darah, Fakultas Kedokteran Universitas Udayana RSUP Sanglah Denpasar, Bali, Indonesia; 2Departemen IImu Penyakit Jantung dan Pembuluh Darah, Fakultas Kedokteran Universitas UdayanaRSUP Sanglah Denpasar, Bali, Indonesia.

\section{*Korespondensi:}

Tjok Ngurah Prasanta Adityaputra; Residen Ilmu Penyakit Jantung dan Pembuluh Darah, Fakultas Kedokteran Universitas Udayana RSUP Sanglah Denpasar, Bali, Indonesia; tjokadit89@gmail.com

Diterima: 12-03-2021

Disetujui: 15-06-2021

Diterbitkan: 22-06-2021

Keywords: thromboangitis obliterans, buerger's disease, raynaud's phenomenon.

Cite This Article: Adityaputra, T.N.P., Sutanegara, B.A.P.D., Suwirya, A.P. 2021. Diagnosis dan tatalaksana tromboangitis obliterans/penyakit buerger dengan fenomena raynaud. Intisari Sains Medis 12(2): 433-436. D0I: 10.15562/ism.v12i2.999

\section{ABSTRAK}

Pendahuluan: Tromboangitis obliterans (TA0) adalah penyakit inflamasi nonaterosklerotik segmental yang melibatkan arteri, vena, dan saraf kecil dan sedang pada ekstremitas. TA0 atau penyakit Buerger memiliki hubungan yang sangat kuat dengan penggunaan tembakau. Penerapan kriteria diagnostik yang lebih ketat dan pengurangan penggunaan tembakau telah menyebabkan penurunan jumlah pasien baru TAO di Amerika Serikat, Eropa, dan Asia. Tipikal pasien TAO adalah pria muda dengan riwayat perokok berat yang muncul dengan gejala iskemik ekstremitas sebelum usia 45 tahun. Gejala paling umum akibat penyakit oklusi arteri, vasospasme sekunder (fenomena Raynaud), dan tromboflebitis superfisial. Diagnosis klinis TAO membutuhkan eksklusi penyakit yang menyerupai penyakit tersebut seperti penyakit pembuluh darah aterosklerotik, penyakit tromboemboli, dan penyakit autoimun seperti scleroderma. Landasan terapi untuk TAO adalah penghentian total setiap penggunaan tembakau. Penggunaan vasodilator pada pasien dengan TAO sebagian besar bersifat paliatif. Antikoagulan terapeutik belum pernah terbukti secara efektif dalam pengobatan TAO. Meskipun demikian, beberapa dokter telah menggunakan antikoagulan dalam upaya untuk menunda amputasi dan meningkatkan aliran kolateral pada iskemia ekstremitas kritis yang berat.

Laporan kasus: Seorang laki-laki berusia 56 tahun mengeluh kebiruan dan nyeri pada ujung kedua jari tangan kanan dan kiri. Merokok empat bungkus sehari. Temuan dupplex ultrasound dan CT scan angiografi ekstremitas superior menunjukkan tidak ditemukan kelainan pada arteri proksimal. Pemeriksaan 
ekokardiografi juga menunjukkan hasil dalam batas normal.

Simpulan:

Dari temuan-temuan

tersebut mengarahkan diagnosis pasien dengan tromboangitis obliterans dengan fenomena Raynaud, walaupun usia sudah lebih dari 45 tahun.

Kata kunci: tromboangitis obliterans, penyakit buerger, fenomena raynaud.

Sitasi Artikel ini: Adityaputra, T.N.P., Sutanegara, B.A.P.D., Suwirya, A.P. 2021. Diagnosis dan tatalaksana tromboangitis obliterans/penyakit buerger dengan fenomena raynaud. Intisari Sains Medis 12(2): 433-436. D0I: 10.15562/ism.v12i2. 999

\section{PENDAHULUAN}

Tromboangitis obliterans (TAO) adalah penyakit inflamasi nonaterosklerotik segmental yang melibatkan arteri, vena, dan saraf kecil dan sedang pada ekstremitas. ${ }^{1}$ TAO, juga disebut sebagai penyakit Buerger, memiliki patofisiologis yang sangat kuat hubungannya dengan penggunaan tembakau, biasanya perokok berat. Spesimen pemeriksaan histopatologis amputasi dari pasien ini menunjukkan proliferasi intimal, trombosisluminal, danfibrosis, merupakan suatu endarteritis dan endoflebitis yang berbeda dari aterosklerosis. ${ }^{2}$

Penerapan kriteria diagnostik yang lebih ketat dan pengurangan penggunaan tembakau telah menyebabkan penurunan jumlah pasien baru yang dilaporkan didiagnosis dengan TAO di Amerika Serikat dan Eropa. Kejadian TAO juga tampaknya menurun di Asia Selatan dan Jepang. Selama tahun 1990-an, rasio pasien baru dengan TAO dibandingkan pasien baru dengan PAD aterosklerotik dilaporkan 1:3 di klinik rawat jalan vaskular di Jepang. Sejak tahun 2000, rasionya telah menurun menjadi $1: 10 .^{3}$

Menurunnya kejadian TAO dan pentingnya tatalaksana untuk mencegah amputasi menjadikan kasus berikut sangat penting agar diagnosis TAO lebih awal dan mendapat tatalaksana segera.

\section{ILUSTRASI KASUS}

Seorang laki-laki berusia 56 tahun, datang dengan keluhan kebiruan dan nyeri pada ujung kedua jari tangan kanan dan kiri. Nyeri sejak dua minggu kemudian memberat seiring berjalannya waktu. Nyeri memberat saat udara dingin, disertai perubahan warna kulit di ujung jari tangan kanan dan kiri. Awalnya tampak pucat dan dingin pada ujung jari tangan, kemudian menjadi kebiruan dan nyeri. Pasien merokok sejak usia remaja. Merokok empat bungkus sehari sejak 24 tahun yang lalu. Riwayat kebiasaan pasien adalah pasien seorang pelari, rutin lari $5 \mathrm{~km}$ per hari, tidak mengeluh sesak maupun nyeri pada tungkai bawah. Pemeriksaan tanda vital dalam batas normal. Pemeriksaan fisik dalam batas normal kecuali pemeriksaan tangan kanan dan kiri pasien. Pemeriksan ujung jari tangan kanan dan kiri (Gambar 1) tampak warna kebiruan, dingin, nyeri, motorik baik, pulsasi arteri radialis kanan dan kiri baik. Saturasi jari tangan kanan I: 82\%, II: 97\%, III: 44\%, IV: 57\%, V: 95\%. Saturasi jari tangan kiri I: $89 \%$, II: 54\%, III, 95\%, IV: 41\%, V: 39\% (Tabel 1). Pemeriksaan darah lengkap dan kimia darah dalam batas normal.

Hasil ekokardiografi menunjukkan normal ekokardiogram, tidak tampak kelainan struktur maupun sumber emboli dari jantung. Hasil dupplex ultrasonografi menunjukkan tidak ada stenosis dan aneurisma pada arteri subclavia, axilaris, brachialis, arteri radialis, arteri ulnaris kanan maupun kiri. Kurva Doppler monofasik yang menandakan stenosis berat ditemukan pada arteri princeps pollicis kanan dan kiri, arteri metakarpal dorsales I kanan dan kiri, dan arteri metakarpal dorsales III kiri. Tidak didapatkan aliran darah pada arteri metakarpal dorsales II kanan dan kiri serta arteri metakarpal dorsales III kanan.

Terapi yang diberikan adalah UFH 5000 IU bolus iv lalu dilanjutkan 20.000 IU dalam 24 jam, cilostazol $50 \mathrm{mg}$ dalam 12 jam, beraprost $15 \mathrm{mg}$ tiap 12 jam, dan antinyeri parasetamol dan ketorolac. Pasien juga disarankan stop merokok. Selama rawat inap tiga hari keluhan nyeri dan kebiruan ujung jari membaik.

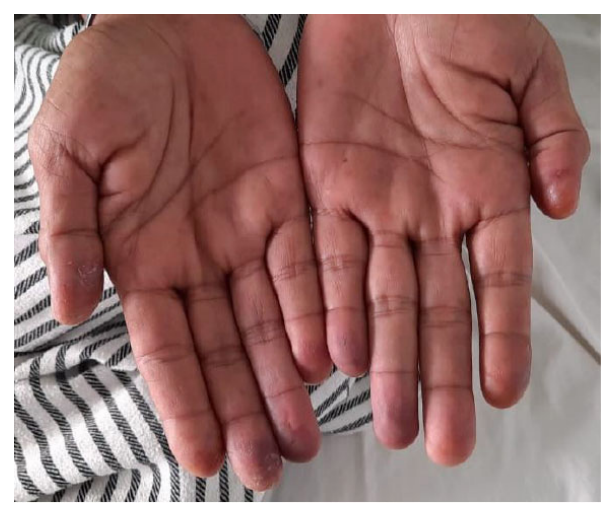

Gambar 1. Pemeriksaan fisik ekstremitas superior kanan dan kiri tampak ujung jari kebiruan

Saat pasien di poliklinik setelah pulang dari rawat inap dilakukan pemeriksaan CT scan angiografi ekstremitas superior kanan dan kiri dengan hasil stenosis parsial pada percabangan arteri setinggi arkus palmar superfisialis metacarpal 4 dan 5 dekstra. Tak tampak stenosis pada sistem arteri sinistra. Tak tampak soft plaque dan kalsifikasi di sepanjang arteri ulnaris dan radialis, arteri arkus palmaris superfisialis dan profunda, arteri pollicis princeps bilateral.

\section{PEMBAHASAN}

Pada kasus di atas, laki-laki 56 tahun, merokok 4 bungkus sehari, mengeluh kebiruan dan nyeri pada ujung jari kedua tangan sejak dua minggu sebelum masuk rumah sakit. Paparan tembakau sangat penting untuk inisiasi, pemeliharaan, dan perkembangan TAO. Hubungan antara penggunaan berat tembakau dan TAO begitu kuat sehingga dianggap esensial untuk diagnosis. ${ }^{2}$

Tipikal pasien TAO adalah pria muda dengan riwayat perokok berat tembakau 
Tabel 1. Saturasi oksigen perifer tangan kanan dan kiri selama rawat inap dan poliklinik

\begin{tabular}{ccc}
\hline Hari Perawatan & $\begin{array}{c}\text { Saturasi Jari Tangan Kanan I/ II/ } \\
\text { III/ IV/V (\%) }\end{array}$ & $\begin{array}{c}\text { Saturasi Jari Tangan Kiri I/ II/ } \\
\text { III/ IV/ V (\%) }\end{array}$ \\
\hline Hari ke-1 (H1) & $82 / 97 / 44 / 57 / 95$ & $89 / 54 / 95 / 41 / 39$ \\
H2 & $76 / 95 / 91 /-/ 98$ & $77 / 75 / 99 / 62 /-$ \\
H3 & $89 / 99 / 75 / 99 / 99$ & $99 / 99 / 99 / 98 / 99$ \\
H4 & $98 / 99 / 76 / 98 / 88$ & $82 / 99 / 66 / 99 / 99$ \\
\hline
\end{tabular}

Tabel 2. Sistem skoring Papa untuk diagnosis penyakit buerger

\begin{tabular}{lll} 
Positive criteria & & Points \\
\hline Age at onset & $<30$ / 30-40 years & $+2 /+1$ \\
Foot claudication & Present / by history & $+2 /+1$ \\
Upper extremity involement & Symptomatic / asymptomatic & $+2 /+1$ \\
Migrating superficial vein thrombosis & Present / by history only & $+2 /+1$ \\
Raynaud syndrome & Present / by history only & $+2 /+1$ \\
Angiography, biopsi & Both typical / either & $+2 /+1$ \\
\hline Negative criteria & & Points \\
\hline Age at onset & $45-50 />50$ years & $-1 /-2$ \\
Sex, smoking & Female / nonsmoker & $-1 /-2$ \\
Location & Single limb / not in lower extremity & $-1 /-2$ \\
Absent pulses & Brachial / femoral & $-1 /-2$ \\
Arteriosclerosis, diabetes, hypertension, & Discovered later 5-10 / 2-5 years & $-1 /-2$ \\
hyperlipidemia & & \\
\hline
\end{tabular}

yang muncul dengan gejala iskemik ekstremitas sebelum usia 45 tahun. $^{4}$ Usia pasien yang sudah melewati usia 45 tahun membuat diagnosis banding selain Buerger's disease adalah penyakit aterosklerosis dan tromboemboli akibat penyakit kardiovaskular maupun penyakit arteri proksimal.

Gejala paling umum TAO adalah akibat dari penyakit oklusi arteri, vasospasme sekunder (fenomena Raynaud), dan tromboflebitis superfisial. ${ }^{2}$ Penyakit oklusi arteri akibat TAO paling sering muncul sebagai gejala intermiten klaudikasio pada kaki, tungkai, tangan, atau lengan. Keluhan utama lainnya adalah kaki dingin, perubahan warna, nyeri istirahat, dan ulkus nekrotik. ${ }^{5}$ Sensitif terhadap dingin merupakan salah satu dari manifestasi awal penyakit. ${ }^{6}$ Ekstremitas, khususnya jari, ditandai oleh rubor atau sianosis.

Pemeriksaan fisik pasien dengan dugaan TAO harus termasuk evaluasi vaskular rinci dengan palpasi denyut nadi perifer, auskultasi untuk bising arteri, dan pengukuran indeks pergelangan kaki: brakialis. Tangan dan kaki diperiksa untuk menemukan iskemia jari. Pemeriksaan neurologis dapat mendokumentasikan keterlibatan saraf perifer dalam bentuk defisit sensorik. Meski nonspesifik, tes
Allen abnormal pada perokok muda dengan iskemia digital sangat sugestif TAO karena merupakan bukti penyakit pembuluh darah kecil. ${ }^{4}$ Pemeriksan ujung jari tangan kanan dan kiri pasien di atas tampak warna kebiruan, dingin, nyeri, motorik baik, pulsasi arteri radialis dan ulnaris kanan kiri baik. Saturasi ujung jari tangan kanan I: $82 \%$, II: 97\%, III: 44\%, IV: 57\%, V: $95 \%$. Saturasi ujung jari tangan kiri I: $89 \%$, II: $54 \%$, III, $95 \%$, IV: $41 \%$, V: $39 \%$. Hal ini menunjukkan kelainan terjadi pada pembuluh darah arteri kecil setelah arteri radialis dan ulnaris kanan kiri sesuai dengan predisposisi penyakit TAO.

Pencitraan pada pasien dengan dugaan TAO tidak hanya digunakan untuk menegakkan diagnosis tetapi juga untuk menyingkirkan diagnosis banding. Misalnya, ekokardiografi sering diindikasikan untuk menyingkirkan sumber emboli jantung yang mengakibatkan oklusi arteri akut. Demikian juga, angiografi dengan kateterisasi selain bisa mencari bukti TAO, juga untuk mengeksklusi sumber emboli arteri proksimal ke arteri distal. ${ }^{4}$ Keterlibatan arteri distal kecil-menengah, oklusi segmental, dan kolateral corkscrewshaped di sekitar area oklusi adalah temuan angiografik yang khas pada TAO. Kolateral corkscrew tidak spesifik untuk TAO, bagaimanapun, bisa diamati pada penyakit yang menyebabkan oklusi pembuluh kecil. Meskipun kemajuan dalam CT-angiografi dan MR-angiografi telah menunjukkan harapan untuk pencitraan pembuluh darah distal, sebagian besar pasien akan membutuhkan angiografi berbasis kateter untuk memberikan resolusi spasial yang diperlukan untuk mendeteksi patologi arteri kecil, terutama pada tangan dan kaki. $^{7}$ Pemindaian dupleks arteri juga bisa digunakan untuk menyingkirkan lesi aterosklerotik proksimal dan mengidentifikasi penyakit oklusi arteri distal. ${ }^{9}$ Ultrasonografi aorta abdominalis dapat digunakan untuk menyingkirkan aneurisma aorta abdominal atau aterosklerosis sebagai sumber embolisasi distal ke ekstremitas bawah. Temuan iregularitas dinding arteri, kalsifikasi vaskular, dan keterlibatan arteri proksimal membuat diagnosis TAO dipertanyakan. ${ }^{4}$

Pada kasus di atas, hasil ekokardiografi menunjukkan normal ekokardiogram, tidak tampak kelainan struktur maupun sumber emboli dari jantung. Hasil dupplex ultrasonografi menunjukkan tidak ada stenosis dan aneurisma pada arteri subclavia, axilaris, brachialis, arteri radialis, arteri ulnaris kanan maupun kiri. Kurva Doppler monofasik yang menandakan stenosis berat ditemukan pada arteri princeps pollicis kanan dan kiri, arteri metakarpal dorsales I kanan dan kiri, dan arteri metakarpal dorsales III kiri. Tidak didapatkan aliran darah yang menunjukkan sumbatan total pada arteri metakarpal dorsales II kanan dan kiri serta arteri metakarpal dorsales III kanan. Dikonfirmasi juga dengan pemeriksaan CT scan angiografi ekstremitas superior kanan dan kiri dengan hasil stenosis parsial pada percabangan arteri setinggi arkus palmar superfisialis metacarpal 4 dan 5 dekstra. Tak tampak stenosis pada sistem arteri sinistra. Tak tampak soft plaque dan kalsifikasi di sepanjang arteri ulnaris dan radialis, arteri arkus palmaris superfisialis, profunda, dan arteri pollicis princeps bilateral. Dari temuan pencitraan pada pasien di atas mengarahkan diagnosis ke tromboangitis obliterans (Buerger's disease), walaupun usia sudah lebih dari 45 tahun. 
Beberapa kriteria diagnostik telah diajukan untuk evaluasi pasien dengan dugaan TAO. Papa dan Adar mengusulkan kriteria yang menggabungkan klinis, angiografi, histopatologi, dan elemen eksklusi, dan kemudian merancang sistem penilaian poin untuk diagnosis $\mathrm{TAO}^{7}$ Keuntungan dari kriteria penilaian ini dibandingkan kriteria lainnya adalah bahwa pasien dapat diklasifikasikan secara objektif. Kepastian diagnosis juga dapat dihitung sebagai "definite" (6 poin atau lebih), "probable" (4-5 poin), "suspected" (2-3 poin), atau "excluded" (0-1 poin) (Tabel 2). Jika pasien bukan perokok, diagnosis positif penyakit Buerger harus disingkirkan. ${ }^{8}$

Landasan terapi untuk TAO adalah penghentian total setiap penggunaan tembakau. Bahkan beberapa batang rokok sehari dapat menyebabkan perkembangan penyakit dan berujung pada amputasi. ${ }^{1}$ Penggunaan vasodilator pada pasien dengan TAOsebagian besarbersifatpaliatif. Vasodilator yang paling sering digunakan dalam praktik klinis untuk pasien TAO datang dari uji coba yang mengevaluasi analog prostasiklin iloprost. Iloprost dapat dipertimbangkan untuk pasien dengan TAO yang memiliki iskemia tungkai kritis dan untuk mengurangi nyeri di awal masa pengobatan sementara mereka menghentikan penggunaan tembakau. ${ }^{4}$ Penghambat fosfodiesterase (PDE) dengan efek vasodilator memiliki potensi untuk berperan dalam pengelolaan TAO, tetapi membutuhkan evaluasi dalam uji coba prospektif. Meski tidak secara khusus dijelaskan pada pasien dengan TAO, cilostazol telah dilaporkan membantu penyembuhan ulserasi iskemik pada pasien yang tidak memenuhi syarat untuk revaskularisasi. ${ }^{10}$ Meskipun itu membantu dalam mengobati klaudikasio akibat penyakit vaskular aterosklerotik perifer, pengalaman klinis dengan cilostazol untuk ini indikasi pada pasien dengan TAO terbatas. Terapi alternatif lain yang masih belum terbukti dalam pengobatan pasien dengan TAO lainnya adalah antikoagulan. Antikoagulan terapeutik belum pernah ada terbukti secara efektif dalam pengobatan TAO. Meskipun demikian, beberapa dokter telah menggunakan antikoagulan dalam upaya untuk menunda amputasi dan meningkatkan aliran kolateral pada iskemia ekstremitas kritis yang berat. ${ }^{11}$ Pada kasus di atas, terapi yang diberikan adalah UFH 5000 IU bolus iv lalu dilanjutkan 20.000 IU dalam 24 jam, cilostazol $50 \mathrm{mg}$ dalam 12 jam, beraprost $15 \mathrm{mg}$ tiap 12 jam, dan antinyeri parasetamol dan ketorolac. Pasien juga disarankan stop merokok. Selama rawat inap tiga hari keluhan nyeri dan kebiruan ujung jari membaik.

\section{SIMPULAN}

Kasus di atas memberi gambaran bahwa pasien usia lebih dari 45 tahun dengan riwayat merokok empat bungkus sehari masih dapat didiagnosis penyakit tomboangitis obliteran dengan fenomena Raynaud. Diagnosis ini didapat setelah mengeksklusi penyakit aterosklerosis dan tromboemboli akibat penyakit kardiovaskular maupun penyakit arteri proksimal yang biasa ditemui pada pasien yang lebih tua. Temuan dupplex ultrasound dan CT scan angiografi ekstremitas superior menunjukkan tidak ditemukan kelainan pada arteri proksimal. Pemeriksaan ekokardiografi juga menunjukkan hasil dalam batas normal. Landasan terapi untuk TAO adalah penghentian total setiap penggunaan tembakau. Prognosis pasien TAO sangat bergantung pada kemampuannya untuk menghentikan penggunaan tembakau.

\section{KONFLIK KEPENTINGAN}

Penulis melaporkan tidak ada konflik kepentingan.

\section{PENDANAAN}

Pada penulisan laporan kasus ini, tidak ada dana yang dikeluarkan maupun pemberian dana oleh pihak manapun.

\section{ETIKA DALAM PENELITIAN}

Pasien telah menandatangani secara tertulis lembar informed consent untuk foto klinis, data klinis dari pasien dapat dipublikasikan pada jurnal ilmiah kedokteran.

\section{KONTRIBUSI PENULIS}

Tjok Ngurah Prasanta Adityaputra bertanggung jawab terhadap evaluasi kasus, penulisan naskah publikasi, dan monitoring harian kasus. Bagus Ari Pradnyana Dwi Sutanegara dan Agung Pradnyana Suwirya bertanggung jawab terhadap supervisi kasus dan membimbing dalam penyusunan naskah publikasi.

\section{DAFTAR PUSTAKA}

1. Piazza G, Creager MA: Thromboangiitis obliterans. Circulation. 2010;121:1858-1861. DOI: 10.1161/ CIRCULATIONAHA.110.942383

2. Igari K, Inoue Y, Iwai T. The epidemiologic and clinical findings of patients with Buerger disease. Annals of Vascular Surgery. 2016;30:263-9. DOI: 10.1016/j.avsg.2015.07.014

3. Watanabe $\mathrm{Y}$, Miyata $\mathrm{T}$, Shigematsu $\mathrm{K}$, Tanemoto K, Nakaoka Y, Harigai M. Current Trends in Epidemiology and Clinical Features of Thromboangiitis Obliterans in Japan-A Nationwide Survey Using the Medical Support System Database. Circulation Journal. 2020:CJ19. DOI: $10.1253 /$ circj.CJ-19-1165

4. Creager M, Loscalzo J, Beckman JA. Vascular Medicine E-Book: A Companion to Braunwald's Heart Disease. Elsevier Health Sciences; 2012.

5. Małecki R, Kluz J, Przeździecka-Dołyk J, Adamiec R. The pathogenesis and diagnosis of thromboangiitis obliterans: is it still a mystery. Adv Clin Exp Med. 2015;24(6):1085-97. DOI: 10.17219/acem/33322

6. Tavakoli H, Rezaii J, Esfandiari K, et al: Buerger's disease: a 10-year experience in Tehran, Iran, Clin Rheumatol. 2008;27:369-371. DOI: 10.1007/s10067-007-0784-x

7. Akar AR, İnan MB, Baran Ç. Thromboangiitis obliterans. Current Treatment Options in Rheumatology. 2016;2(2):178-95. DOI: 10.1007/s40674-016-0047-6

8. Sugimoto M, Komori K. Buerger's Disease (Thromboangiitis Obliterans). In Systemic Vasculitides: Current Status and Perspectives. Springer, Cham; 2016. p. 361-376.

9. Fujii Y, Teragawa H, Kihara Y, Higashi Y. Corkscrew collaterals in Raynaud's syndrome. Case Reports. 2016;2016:bcr2016215841. DOI: 10.1136/bcr-2016-215841

10. Diaz-Sandoval LJ. The Long-Term Care of Patients with Critical Limb Ischemia (CLI). InCritical Limb Ischemia. Springer, Cham; 2017. p. 641-650.

11. Decousus H, Prandoni P, Mismetti P. Fondaparinux for the treatment of superficialvein thrombosis in the legs. N Engl J Med. 2010;363:1222-1232. DOI: 10.1056/ NEJMoa0912072

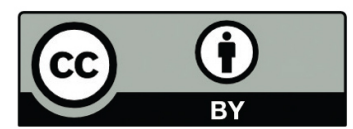

This work is licensed under a Creative Commons Attribution 